\title{
SOBRE A EXPANSIVIDADE DA DEMOCRACIA: UMA PROPOSTA DE REINTERPRETAÇÃO DO MINIMALISMO DEMOCRÁTICO
}

\author{
SOBRE LA EXPANSIVIDAD DE LA DEMOCRACIA: UNA PROPUESTA DE \\ REINTERPRETACIÓN DEL MINIMALISMO DEMOCRÁTICO
}

\author{
ON THE EXPANSIVITY OF DEMOCRACY: A PROPOSAL FOR \\ REINTERPRETATION OF DEMOCRATIC MINIMALISM
}

\author{
Sérgio Mendonça BENEDITO ${ }^{1}$
}

RESUMO: Este ensaio bibliográfico visa reconsiderar as proposições do minimalismo democrático de Joseph Schumpeter e, por meio desse exercício, examinar como seu núcleo conceitual se amplifica no efetivo funcionamento da democracia. Após uma breve síntese do minimalismo schumpeteriano, apresentamos algumas críticas que lhe foram direcionadas a partir dos anos 1960. Por fim, com base em O'Donnell, Saffon e Urbinati, propomos um alargamento do procedimentalismo de modo que este contemple uma dimensão normativa. Essa discussão teórico-conceitual, ainda que limitada, mostra-se relevante na atualidade em vista dos desafios colocados aos (às) cientistas sociais para identificar com rigor científico quais países são de fato democráticos - apesar de realizarem eleições regulares.

PALAVRAS-CHAVE: Teoria democrática. Minimalismo. Procedimentalismo. Representação política.

RESUMEN: Este ensayo bibliográfico visa reconsiderar las propociones del minimalismo democrático de Joseph Schumpeter y, por ese ejercício , examinar como su núcleo conceptual se amplifica en el efetivo funcionamiento de la democracia. Tras una breve síntesis del minimalismo schumpeteriano, presentamos algunas críticas que le fueron direccionadas a partir de los años 1960. Por fin, basado en O'Donnell, Saffon e Urbinati, proponemos por una expansión del procedimentalismo de manera que éste contemple una dimensión normativa. Esa discusión teórico-conceptual, aunque limitada, se muestra relevante en la actualidad en vista de los desafíos colocados a las científicas y científicos sociales para identificar con rigor científico cuales países son efetivamente democráticos - pese a de realizaren turnos electorales regulares.

PALABRAS CLAVE: Teoría democrática. Minimalismo. Procedimentalismo. Representación Política.

ABSTRACT: This bibliographic essay aims to reconsider the propositions of Joseph Schumpeter's democratic minimalism and, through this exercise, to examine how its conceptual core is amplified in the effective funcioning of democracy. After a brief analysis of the schumpeterian minimalism, we present some criticisms that were directed to it from the 1960s

1 Universidade Federal de Goiás (UFG), Goiânia - GO - Brasil. Mestre em Ciência Política. ORCID: https://orcid.org/0000-0002-0982-462>. E-mail: sergiombk@gmail.com 
onwards. Finally, based on O'Donnell, Saffon and Urbinati, we propose an extension of proceduralism so that it contemplates a normative dimension. This theoretical-conceptual discussion, however limited, is relevant today in the occasion of the challenges faced by social scientists to identify with scientific rigor which countries are indeed democratic - despite holding periodic elections.

KEYWORDS: Democratic theory. Minimalism. Proceduralism. Political representation.

\section{Introdução ${ }^{2}$}

A pouco mais de uma década se fortalece a discussão sobre a crise da democracia e seus efeitos institucionais concretos. Nesse contexto, especialistas divergem sobre em que momento um regime específico deixou de ser intrinsecamente democrático e que aspectos foram comprometidos a ponto de tornar aquele país menos liberal. O parâmetro procedimental consenso básico sobre as regras, manutenção das instituições políticas, eleições limpas e livres - segue recorrente em diversas análises (GLASIUS, 2018). Contudo é necessário ponderar, para além da forma, sobre o conteúdo da democracia. Afinal, mesmo o critério mínimo de eleições demanda a conformação de uma sociedade política plural e que dê condições para que essa competição se efetue plenamente, com amplas liberdades civis e políticas. A mensuração do que vem ou não a ser um regime democrático, portanto, passa por uma avaliação qualitativa dependente de um conceito mais denso de democracia.

Relacionando-se ao fundamento teórico-conceitual desse debate, este ensaio visa explorar o argumento de que não é possível restringir a definição de democracia ao critério da livre disputa eleitoral entre elites abstendo-se dos requisitos para a efetividade dessa competição. Mesmo aqueles autores que em algum momento se identificaram com o minimalismo democrático chegam contemporaneamente a reconhecer que "o termo democracia não tem... apenas uma função descritiva ou denotativa, mas também... normativa e persuasiva" (SARTORI, 1994, p. 24). Por isso é necessário admitir que mesmo as definições mais restritas propiciam a ampliação do que se entende por sociedade democrática quanto a valores e liberdades. Assim, abre-se a possibilidade de um entendimento forte da cidadania como desdobramento do próprio núcleo das proposições minimalistas.

\footnotetext{
${ }^{2}$ Uma versão ampliada e preliminar deste texto foi apresentada como trabalho final na disciplina "Teoria Política 2", ministrada pela Profa. Dra. Camila Romero Lameirão no Programa de Pós-graduação em Ciência política da Universidade Federal de Goiás (PPGCP/UFG) no segundo semestre letivo de 2016. Meus agradecimentos à profa. Camila e ao colega Lucas Gabriel Costa pelos comentários referentes ao texto. Todos os trechos transcritos de obras em inglês foram traduzidos pelo autor.
} 
O texto está dividido em duas partes. Na primeira seção, busco caracterizar resumidamente o minimalismo democrático recorrendo às formulações de Schumpeter (1961). Na parte seguinte, abordo algumas críticas que foram feitas a essa definição mínima e pontos de abertura para um entendimento mais amplo da democracia a partir do procedimentalismo favorecendo-me em especial dos argumentos de Walker (1966), Pateman (1992), O’Donnell (1999), Saffon e Urbinati (2013). As considerações finais sintetizam os argumentos apresentados e sinalizam porque as democracias na atualidade não podem ser avaliadas segundo uma leitura restrita do minimalismo de base schumpeteriana.

\section{O minimalismo democrático schumpeteriano}

Joseph Alois Schumpeter (1883-1950) foi um autor austríaco que se tornou célebre em especial na área da economia, tratando temas como o desenvolvimento e o papel dos empreendedores na dinâmica econômica. Em Capitalismo, socialismo e democracia, publicado originalmente em 1942, o autor se deteve a estudar o socialismo ou, mais especificamente, sobre como o desenvolvimento exitoso do capitalismo daria lugar a essa forma de organização da sociedade (SWEDBERG, 2003).

Nas décadas seguintes, contudo, a obra despontaria como referência no campo da ciência política por suas considerações a respeito do conceito de democracia, além da crítica ao que ele classificou como a sua 'teoria clássica'. Com isso, seu propósito foi elaborar uma teoria realista do processo democrático que enfatizasse a luta pelo poder político. Dado o contexto em que o autor escreveu, e a mencionada crítica que elaborou, pode-se compreender a sua ênfase na impossibilidade e incompetência dos cidadãos em participarem na política e, mais que isso, o perigo que tal envolvimento representaria, tendo em conta os acontecimentos que levaram à Segunda Guerra Mundial (1939-1945) - em especial na Alemanha e na Itália. Com o passar dos anos suas formulações encontrariam eco em pesquisas desenvolvidas nos Estados Unidos que mostravam um eleitorado pouco informado ou capacitado para tomar decisões. Estudos encabeçados por cientistas políticos como Angus Campbell, Philip Converse e Paul Lazarsfeld (MIGUEL, 2014), entre outros, argumentavam que isso não representava um problema para a democracia - pelo contrário, garantia sua estabilidade.

Considerando a obra fundamental de Schumpeter, e mais especificamente ao que escreveu sobre a democracia, o ponto de partida é um experimento mental: seria um país que decide, democraticamente, perseguir cristãos, feiticeiras e judeus, um Estado democrático? 
“Aprovaríamos nós uma Constituição democrática que produzisse tais resultados de preferência a uma não democrática que os evitasse?" (SCHUMPETER, 1961, p. 296). Tais questões servem de base para avançar seu argumento de que o método democrático não abrange qualquer conteúdo ou ideal, necessariamente. Trata-se apenas de "um método político, isto é, um certo tipo de arranjo institucional para chegar a uma decisão política (legislativa ou administrativa) e, por isso mesmo, incapaz de ser um fim em si mesmo, sem relação com as decisões que produzirá em determinadas condições históricas" (SCHUMPETER, 1961, p. 296-297). Para o austríaco, a democracia não produz os mesmos efeitos em todos os lugares e tempos históricos, mas está vinculada às particularidades de um contexto. Não existe problema, por exemplo, que uma determinada comunidade política imponha restrições a uma parcela da população no que se refere ao voto: o que constitui o 'povo' é melhor determinado pela própria sociedade, já que todas possuem alguma forma de restrição (por idade, por incapacidade psíquica), sendo insensato compará-las.

O que seria então o governo do povo? Por um lado Schumpeter destaca que nenhuma forma de governo, seja uma monarquia ou ditadura, pode ignorar completamente as opiniões de sua população e se manter estável - todo governante contempla de alguma forma as vontades de seus súditos, ou seja, um governo para o povo não necessariamente será um governo pelo povo, o que exige uma distinção. Por outro lado, é perfeitamente concebível que o povo governe, como tal, numa comunidade reduzida e pouco diferenciada. Contudo, na medida em que cresce a extensão territorial, o número de pessoas e os interesses envolvidos nos assuntos da comunidade, torna-se tecnicamente impossível que exista um 'governo do povo' no real sentido da expressão ${ }^{3}$. A solução encontrada por Schumpeter para tal problema é definir o governo do povo como o governo aprovado ou autorizado pelo povo. Assim, “o povo jamais governa, mas pode sempre governar por definição" (SCHUMPETER, 1961, p. 301), não sendo apropriado associar a democracia a uma configuração específica, como a democracia direta - já que existem tantas outras formas de participação e influência dos cidadãos nos assuntos públicos. Tal definição, conforme seu argumento, satisfaria mesmo àqueles que definem a democracia de maneira mais substantiva, elencando suas virtudes no que se refere ao bem comum da comunidade.

Tendo definido a democracia como um método para a tomada de decisões políticas e o governo do povo como aquele que é autorizado pelos cidadãos por meio do voto, o austríaco

3 Para Schumpeter não pode existir qualquer tipo de 'mandato imperativo', dado que a independência dos representantes com relação aos representados é "um princípio... que foi reconhecido por todas as constituições e teorias políticas desde o tempo de Edmund Burke" (SCHUMPETER, 1961, p. 357). 
procede à crítica do que ele chama de 'teoria clássica' da democracia. Seu ataque se concentra principalmente em questionar os conceitos de bem comum e vontade comum, que atribuem um caráter irrealista à representação política e tomada de decisões em uma sociedade. Schumpeter (1961) argumenta que não existe um bem comum que seja equivalente para toda a população de uma comunidade. Nesse sentido, as pessoas podem possuir diferentes concepções de bem, do que elas acreditam ser o melhor para a comunidade, e isso não é facilmente compatibilizável. Além disso, mesmo que exista acordo sobre uma determinada concepção de bem, a maneira como chegar a ela ou a solução adequada pode divergir entre as pessoas. Por consequência, não se pode falar em uma vontade geral, já que ela exige um comum entendimento e compreensão do que é melhor para a comunidade - as vontades individuais podem não convergir para uma vontade geral.

$\mathrm{O}$ ataque à teoria clássica da democracia se faz também pelo questionamento da racionalidade política individual. Nesse sentido Schumpeter afirma que:

[...] ficamos ainda obrigados por necessidade prática a atribuir à vontade do indivíduo uma independência e uma qualidade racional que são absolutamente irrealistas. Para argumentar que a vontade do cidadão per se é um fator político digno de respeito, essa vontade deve, em primeiro lugar, existir. Ou melhor, deve ser algo mais do que um conjunto indeterminado de impulsos vagos, circulando frouxamente em torno de slogans e impressões errôneas (SCHUMPETER, 1961, p. 309).

Identifica-se assim uma limitada capacidade do cidadão em si mesmo de tomar decisões esclarecidas sobre temas políticos sem sofrer influência externa - pelo carisma, pressão de grupos ou propaganda. E, ainda que essa capacidade existisse, seria difícil compor o que se classifica como uma vontade geral - no sentido de conduzir a uma ação satisfatória, que contemple aos diferentes entendimentos da questão. O pressuposto dessas formulações é o de que existe uma 'natureza humana política' que restringe a capacidade dos indivíduos em realizarem julgamentos racionais sobre problemas relacionados à política de uma comunidade. Nesse ponto Schumpeter estava informado pela psicologia política e as considerações de Le Bon sobre o comportamento das massas. Em síntese, “o cidadão típico... desce para um nível inferior de rendimento mental logo que entra no campo político... Torna-se primitivo novamente. O seu pensamento assume o caráter puramente associativo e afetivo" (SCHUMPETER, 1961, p. 320). Atacar a teoria clássica, como assim a chama e define, equivale a atacar também o pressuposto de que os cidadãos são capazes de deliberar e tomar decisões políticas em conjunto - o que ele classifica como uma "ficção" (SCHUMPETER, 1961, p. 323) -, atribuindo essa incapacidade a uma qualidade inerente do ser humano. 
Se a chamada teoria clássica da democracia coloca em segundo plano a eleição dos representantes e em primeiro a capacidade dos cidadãos ponderarem definida e racionalmente sobre temas políticos, Schumpeter visa inverter essa relação e atribuir ao eleitor apenas e tão somente a função de formar governos. Em sua definição, "o método democrático é um sistema institucional, para a tomada de decisões políticas, no qual o indivíduo adquire o poder de decidir mediante uma luta competitiva pelos votos do eleitor" (SCHUMPETER, 1961, p. 328). Tal definição teria, entre outras, as seguintes vantagens: colocar em destaque a função do líder de governo, o que é omitido na teoria clássica; não negligenciar os interesses coletivos organizados - que manifestam sua vontade por meio de pautas específicas, reconhecidas pelos representantes; estabelecer um vínculo mais claro entre democracia e liberdades individuais a luta pelo poder propicia a ampliação das liberdades, ainda que não as garanta; clarificar a função dos cidadãos de eleger o governo e não de forçá-lo ou orientá-lo a tomar certas decisões. “O princípio da democracia, então, significa apenas que as rédeas do governo devem ser entregues àqueles que contam com maior apoio do que outros indivíduos ou grupos concorrentes" (SCHUMPETER, 1961, p. 332), o que exclui a necessidade de adotar princípios substantivos, como a representação proporcional.

Essa construção teórica, então, converge para aspectos que viriam a conformar o mainstream da ciência política contemporânea, quais sejam, o papel dos partidos, a disputa política e a profissionalização das elites. Segundo Schumpeter (1961), o objetivo primordial dos partidos é vencer eleitoralmente e conquistar ou manter o poder. Seu papel é o de elaborar, votar leis e adotar procedimentos administrativos na medida em que isso garanta seu sucesso na disputa eleitoral - em suma, eles não se elegem para fazer leis, mas fazem leis para serem eleitos. Outra função importante do partido é de mobilizar os cidadãos em períodos eleitorais, estabelecendo as pautas políticas e programas - o povo não se mobiliza e sim é mobilizado pelas elites. Em síntese, os partidos não servem para promover o bem comum como supostamente postulado pela teoria clássica: "o partido é um grupo cujos membros resolvem agir de maneira concertada na luta competitiva pelo poder político" (SCHUMPETER, 1961, p. 344). Na medida em que o povo não é capaz de outra ação que não o 'estouro da boiada', cabe aos partidos mobilizá-lo por meio da propaganda e criação de pautas políticas - e aqui o líder partidário tem um papel central. Por tudo isso Schumpeter compreende que a atividade política, para ser satisfatória, deve possuir uma dimensão profissional e conformar-se enquanto carreira. Adepto da vertente liberal, ainda que elitista, o austríaco recomenda a formação de uma classe política e burocrática de qualidade que conduzam os assuntos públicos com prudência e sem interferir 
demasiadamente na sociedade. Nesse quadro, os representantes devem ser plenamente independentes, e ao povo cabe apenas a função de reeleger ou não o grupo que detém o poder.

Em síntese, Schumpeter estabeleceu as bases do que viria a se conformar como o minimalismo na teoria política. Nessa concepção, a democracia é um método político para a tomada de decisões, um arranjo procedimental isento de normatividade ou objetivo último. $\mathrm{O}$ governo democrático se funda na autorização da cidadania para que um grupo político restrito e qualificado o represente, de maneira independente, na condução dos assuntos públicos. Existe, portanto, uma clara 'divisão do trabalho político' entre as elites e a população em geral, dada a suposta inabilidade desta última em deliberar e formular propostas coerentes. Se a desqualificação dos cidadãos se atenuou posteriormente, restou a centralidade dos estudos sobre partidos e instituições na disciplina da ciência política. Na seção seguinte, levantarei alguns contrapontos e críticas ao minimalismo postulado por Schumpeter, e alguns desdobramentos que extrapolam a partir de seu núcleo conceitual.

\section{A crítica do minimalismo e sua extrapolação}

Muito do que veio a ser discutido sobre o conceito e a prática da democracia nas décadas posteriores, em especial a partir dos anos 1950 e 1960, remeteu às formulações de Schumpeter, seja em análises favoráveis ou críticas. Desde então a literatura se expandiu grandemente, com estudos teóricos e empíricos que trataram sobre a democracia em suas mais diferentes dimensões. Não sendo possível esgotar neste espaço a discussão a respeito dos desdobramentos do minimalismo na teoria democrática contemporânea, trato nessa seção sobre duas marcantes críticas direcionadas a essa concepção por parte de Jack Walker (1966) e Carole Pateman (1992). A seguir, a partir das formulações de Guillermo O’Donnell (1999), Maria Saffon e Nadia Urbinati (2013), pretendo avançar o argumento de que mesmo segundo os parâmetros do minimalismo a democracia implica em garantias que vão além do núcleo fundamental dessa vertente teórica.

Já nos anos 1960 era possível perceber que o mainstream da ciência política, proveniente em grande medida dos Estados Unidos, tinha se conformado ao que se denominou como minimalismo democrático. Seguindo os desdobramentos da crítica à chamada 'teoria clássica', e a busca por formas mais 'realistas' de definir e mensurar a democracia, configurou-se o que Walker (1966) qualificou como teoria elitista da democracia. Segundo essa perspectiva, assim como vimos em Schumpeter (1961), a ênfase se coloca sobre a formação (eleições) e 
funcionamento (administração e políticas públicas) dos governos, que se fundamentam na eficiência e estabilidade como valores máximos. Assim, a participação efetiva dos cidadãos nos assuntos públicos e o consenso na sociedade sobre o método democrático e as políticas implementadas é descartado em prol do "consenso de elites", em que políticos e grupos de interesse (stakeholders) dialogam e pactuam para manter a estrutura democrática, de modo a conservar suas posições frente a outros grupos (WALKER, 1966, p. 287). Em tal configuração a apatia pública, longe de ser um problema, é uma virtude que auxilia na estabilidade do sistema, possibilitando a continuidade pacífica da disputa política e a adoção das medidas necessárias por parte do governo. Assim, segundo Walker (p. 288), "na versão elitista da teoria... a ênfase se deslocou para as necessidades e funções do sistema como um todo; não existe mais uma preocupação direta com o desenvolvimento humano", esvaziando a democracia dos ideais políticos propostos por teóricos clássicos.

Assim, a crítica de Walker se volta principalmente para as implicações normativas da teoria elitista e sua inadequação aos acontecimentos políticos ocorridos nos Estados Unidos à época em que seu artigo foi escrito. Por um lado, os teóricos elitistas ignoram o fato de que a teoria clássica - que associa autores das mais diversas tendências numa mesma vertente, o que por si só já é problemático como veremos a seguir - é uma perspectiva utópica, que não tinha a pretensão de dar conta do funcionamento da política. Ao buscar aproximar tais formulações ao que observava na prática, os autores elitistas "transformaram a democracia de uma doutrina radical em uma conservadora, removendo sua ênfase distintiva na atividade política popular" e comprometeram seu fundamento normativo (WALKER, 1966, p. 288). E então, ao fazer isso, estreitaram o potencial crítico da teoria democrática, o que tem efeitos na própria avaliação da democracia que os cidadãos realizam. Por outro lado, dada a sua ênfase na estabilidade do sistema político, a teoria elitista tende a naturalizar e tornar desejável a apatia dos cidadãos com relação à política. Ao tornar um elemento contingente em algo comum, e utilizá-lo para explicar como a democracia se beneficia dele, são obscurecidas as desigualdades presentes na sociedade e a indiferença e insatisfação dos cidadãos em relação à política. A supressão do conflito possibilitada por um modelo democrático consensual, levado a cabo por elites e grupos de interesse, não elimina necessariamente o dissenso presente na sociedade, como o próprio autor observa com relação aos protestos realizados por negros entre 1964 e 1965 nos Estados Unidos.

A partir desses argumentos é possível perceber como o desdém da teoria elitista pelo aspecto da cidadania está longe de garantir 'realismo' às suas formulações. Se os autores dessa vertente se preocuparam em grande medida com os efeitos nocivos da ampla participação dos cidadãos nos assuntos públicos e dos conflitos daí provenientes, atribuindo grande importância 
ao papel dos líderes políticos na administração e manutenção do sistema democrático, é preciso reconhecer que uma percepção da política em que os cidadãos influenciam apenas marginalmente e não se envolvem (ou devem se envolver) é pouco realista (WALKER, 1966). A própria configuração institucional dos Estados Unidos, por exemplo, demonstra que existem consideráveis restrições ao comportamento das elites políticas e que essas não podem agir sem pesar os interesses presentes na sociedade. Mais importante, contudo, é que a adoção de várias políticas pode ser explicada por pressões advindas dos cidadãos, na forma dos movimentos sociais. Esses, segundo o autor, atribuem um aspecto dinâmico ao sistema político, evitando que ele se estabilize e deixe de produzir transformações. Assim, o conflito, longe de ser um aspecto que coloca em perigo a democracia, "é uma grande fonte de mudança e inovação" (WALKER, 1966, p. 295). Em suma, a perspectiva elitista adota uma desconfiança injustificada no potencial dos cidadãos e, ao atribuir tamanha importância às elites políticas, comprometem o aspecto normativo da democracia e favorecem o status quo. Além disso, ao naturalizar e tornar desejável a apatia política, tal vertente se mostra um guia inadequado ao estudo dos acontecimentos políticos dos Estados Unidos na década de 1960 por exemplo. O exame da democracia em suas diferentes dimensões, principalmente no que se refere às desigualdades presentes nas sociedades, requer uma ampliação da perspectiva adotada pelos pesquisadores, para além do que é proposto pelos teóricos elitistas.

Outra autora que formulou críticas contundentes ao minimalismo democrático foi Pateman (1992), em seu estudo sobre a participação a partir da teoria política. A autora inicia o seu estudo caracterizando a teoria democrática de Schumpeter e problematizando entre outros pontos o seu "experimento mental", que entra "em conflito com as regras de procedimento necessárias se quisermos chamar de 'democrático' o método político do país" (PATEMAN, 1992, p. 12) com base em Peter Bachrach ${ }^{4}$. Outras críticas direcionam-se à redução da política ao ato de seleção das elites mais preparadas a governar - o que não significa necessariamente uma ampla liberdade para que qualquer cidadão se candidate à liderança - e o enfraquecimento do aspecto participativo dos cidadãos, que se reduz ao voto e discussão - não deve ocorrer qualquer tentativa de influenciar os representantes para além da decisão de aprovar ou rejeitar um partido por meio do voto. Como demonstra Pateman, tais formulações perpassaram significativamente os estudos sobre a democracia realizados por Berelson, Dahl, Sartori e

${ }^{4}$ Mackie (2009, p. 139) expõe um argumento similar, no sentido de que o experimento mental de Schumpeter apresenta "uma falsa dicotomia". Um democrata poderia rejeitar ambas as opções colocadas com base na valorização tanto dos princípios liberais como dos princípios democráticos. 
Eckstein $^{5}$ que, entre outros, compõem o que ela classifica como teoria contemporânea da democracia:

\begin{abstract}
Nessa teoria, a "democracia" vincula-se a um método político ou uma série de arranjos institucionais a nível nacional. O elemento democrático característico do método é a competição entre os líderes (elite) pelos votos do povo, em eleições periódicas e livres. As eleições são cruciais para o método democrático, pois é principalmente através delas que a maioria pode exercer controle sobre os líderes. A reação dos líderes às reivindicações dos que não pertencem à elite é segurada em primeiro lugar pela sanção da perda do mandato nas eleições; as decisões dos líderes também podem sofrer influências de grupos ativos, que pressionam nos períodos entre as eleições [...] Finalmente, "participação", no que diz respeito à maioria, constitui a participação na escolha daqueles que tomam as decisões. Por conseguinte, a função da participação nessa teoria é apenas de proteção; a proteção do indivíduo contra as decisões arbitrárias dos líderes eleitos e a proteção de seus interesses privados. É na realização desse objetivo que reside a justificação do método democrático (PATEMAN, 1992, p. 25).
\end{abstract}

Mas o aspecto central de sua crítica ao minimalismo schumpeteriano, e por tabela a todos que se espelharam em sua categorização da chamada 'teoria clássica', é a percepção de que existe uma teoria clássica da democracia. Constitui-se assim, segundo Pateman (1992), um mito da teoria clássica, dado que nenhum dos autores contemporâneos anteriormente mencionados buscou averiguar a fundo o que os teóricos clássicos postulavam a respeito da democracia. Schumpeter (1961), por exemplo, não menciona nomes quando trata sobre os conceitos de bem comum e vontade comum e quando se refere a essa teoria como individualista, utilitarista e elaborada no século XVIII. Com base nessas indicações a autora chega aos nomes “de Rousseau, os dois Mill e Bentham, que de fato merecem o título de teóricos 'clássicos' da democracia” (PATEMAN, 1992, p. 29).

O que se percebe é que não apenas a caracterização das ideias desses autores é errônea na obra de Schumpeter, mas que não é possível reunir suas diferentes perspectivas sob um único rótulo. Enquanto James Mill e Bentham se preocuparam em especial com os "arranjos institucionais" (PATEMAN, 1992, p. 32) do sistema político, atribuindo à participação um aspecto apenas protetivo - garantindo que os "interesses universais" da comunidade não seriam dispensados pelos representantes - Stuart Mill e Rousseau enfatizaram a participação como um aspecto mais abrangente, "fundamental para o estabelecimento e manutenção do Estado democrático, Estado esse considerado não apenas como um conjunto de instituições representativas nacionais, mas como aquilo que denominei de sociedade participativa"

5 Pateman se refere às obras Voting, de Berelson et al.; A Preface to Democratic Theory e Hierarchy, Democracy and Bargaining in Politics and Economics de Dahl; Democratic Theory de Sartori; e $A$ Theory of Stable Democracy de Eckstein. 
(PATEMAN, 1992, p. 33). No decorrer de sua obra Pateman mostrou como a participação pode ser entendida, a partir desses dois últimos autores, como um elemento capaz de desenvolver as capacidades sociais e políticas dos cidadãos, não se tratando apenas de um método para chegar a decisões políticas.

A partir das críticas de Walker e Pateman, podemos constatar os problemas e os limites do minimalismo tal como proposto por Schumpeter. É necessário reconhecer que o austríaco foi um tanto seletivo em suas críticas à capacidade das pessoas em deliberarem racionalmente sobre os assuntos públicos. Ele deu margem, ainda, ao entendimento de que existem 'especialistas' políticos e que as pessoas devem alienar totalmente as decisões a eles sem questionar seus possíveis interesses e vínculos de classe - como se fosse possível conceber que alguém legisla ou governa por si só, ou que a política é um assunto técnico. Schumpeter, igualmente, foi bastante conservador e preconceituoso ${ }^{6}$ na defesa do elitismo em detrimento da participação popular, e o realismo atribuído à sua teoria no que se refere ao desinteresse ou na incapacidade dos cidadãos compreenderem os assuntos públicos pode ser colocado em questão - apenas fechando os olhos para os conflitos latentes e as desigualdades sociais seria possível postular tal realismo. Some-se a isso que a prática política nas democracias demonstra que a população não permanece inerte a tudo que lhe é imposto e mantém influência sobre seus representantes por outros meios e formas de organização. Tudo isso levado em consideração, no entanto, é possível argumentar que mesmo os parâmetros mínimos estabelecidos pelo autor exigem mais do que é colocado em sua teoria.

Nesse sentido, argumenta O’Donnell (1999) quando destaca que, se Schumpeter reconhece que existe um vínculo entre a 'competição pela liderança' e os 'princípios legais e morais da comunidade' em questão, abre-se uma porta para que a definição minimalista implique em outras qualidades substantivas a esse regime ${ }^{7}$. Compreende-se assim que apenas o fato de existir concorrência política pelo voto, em que as elites políticas terão o papel de mobilizar as massas e construir programas políticos aos quais os últimos possam aderir, pressupõe a existência de liberdades básicas, como a liberdade de expressão ${ }^{8}$. Em suma, "uma

6 "Qualquer pessoa que conheceu Schumpeter pessoalmente pode testemunhar que ele tinha um extenso conhecimento das teorias das elites do final do século dezenove (Nietzsche, Pareto, Mosca, Michels, LeBon) e tomava prazer em flertar com tais ideias" (MARZ, 1991 apud MACKIE, 2009, p. 146). O artigo de Mackie contém outras críticas aprofundadas às proposições de Schumpeter.

${ }^{7}$ Miguel (2014, p. 60) faz um comentário análogo à perspectiva aqui adotada: “E, como Guillermo O’Donnell (1999, p. 582-8) procurou mostrar, mesmo a concepção mínima de democracia em Schumpeter acaba por exigir tais liberdades e direitos [de consciência, expressão, imprensa, associação, manifestação, movimento, etc.], como consequência lógica de sua postulação".

${ }^{8} \mathrm{E}$, eliminado o pressuposto de que apenas algumas pessoas são qualificadas para concorrer eleitoralmente e governar, essas liberdades tornam-se ainda mais importantes e substantivas para o conjunto da população. 
definição elitista da democracia não é necessariamente minimalista" (O’DONNELL, 1999, s. p.). A competição política, que ocorre no tempo em virtude da possibilidade de tanto autorizar como rejeitar um governo, implica "a existência de condições adicionais" (s. p.). Toda uma vertente de autores que se classificaram como minimalistas, como Przeworski e Huntington, apresentam, mesmo que implicitamente, definições de democracia que subentendem a substantiva existência de liberdades civis e políticas para que esse regime seja efetivo.

Até as definições 'minimalistas', 'processualistas' ou 'schumpeterianas', que se limitam a mencionar as eleições competitivas como único elemento característico da democracia, pressupõem a existência de algumas liberdades básicas, ou garantias, para que essas eleições existam. Sendo assim, tais definições não são, nem poderiam ser, minimalistas ou processualistas, como se dizem (O’DONNELL, 1999, s. p.).

Tal interpretação do minimalismo e das proposições de Schumpeter abre caminho para que O’Donnell analise os desdobramentos institucionais da existência de eleições livres e competitivas e das garantias e liberdades de atuação política que as suportam. Para o autor, partindo de tais fundamentos, uma teoria abrangente da democracia teria que incluir também "aspectos da teoria do direito", da estrutura legal que "determina e respalda características fundamentais da democracia", e por conseguinte, ter em conta as especificidades do Estado em que o regime se desenvolve (O’DONNELL, 1999, s. p.). Segundo esse entendimento, a democracia provém da conformação das instituições políticas, a partir da ponderação e das decisões tomadas por uma determinada sociedade, que instituem os parâmetros legais que a regem no que diz respeito aos direitos e obrigações dos cidadãos. Para que esses últimos possuam a capacidade de efetivar seus direitos nessa comunidade - o que o autor concebe pelo conceito de agency ${ }^{9}$-, e para que exista uma estrutura jurídica que sustente "as normas legais que correspondem à existência e persistência de um regime democrático", é necessário uma estrutura estatal eficaz e que promova tais princípios - fatores esses que variam a depender do local e do tempo em análise. De uma concepção de fato minimalista da democracia não poderia derivar uma interpretação equivalente, dada a ênfase na competição eleitoral como condição suficiente da democracia. Não é factível, portanto, encerrar a definição nesse ponto e, por conseguinte, poderíamos mesmo dizer que também não é possível abandonar completamente o componente normativo do método democrático.

9 "Basta dizer que um agente é alguém concebido como dotado de razão prática... que faz uso de sua capacidade cognitiva e motivacional para tomar decisões racionais em termos de sua situação e de seus objetivos, e dos quais, salvo prova conclusiva em contrário, é considerado o melhor juiz” (O’DONNELL, 1999, s. p.). 
Percebendo que a definição clássica do minimalismo é insuficiente para dar conta dos sistemas democráticos tal como se conformam contemporaneamente, e que a justificação normativa da democracia não deve ser abandonada, alguns autores e autoras trabalharam recentemente por uma compreensão ampliada do procedimentalismo. Tal é o caso de Saffon e Urbinati (2013), as quais argumentam que os direitos de voto e discussão não são suficientes para garantir a liberdade de participação. É necessário fomentar em plenitude os direitos civis, políticos e sociais básicos, de forma que todas as pessoas possam ter condições iguais de participar nos assuntos públicos. Não é difícil perceber a convergência da defesa do procedimentalismo com a teoria da representação política de Urbinati (2006): as instituições representativas não se encerram em si mesmas, mais do que isso, promovem um processo político em que os cidadãos tem a possibilidade de debater ideias e apresentar suas concepções. Portanto, a representação "designa uma forma de processo político que é estruturada em termos da circularidade entre instituições e sociedade". A política, assim, não se encerra no ato de autorização/eleição, mas está em constante (re)construção por meio de uma "corrente comunicativa entre sociedade civil e política" (URBINATI, 2006, p. 24).

Em seu artigo, Saffon e Urbinati (2013) buscam diferenciar o procedimentalismo, tal como defendem, de três perspectivas adotadas atualmente: a concepção epistêmica da democracia, o populismo e o minimalismo schumpeteriano. Direcionando-nos à sua análise sobre esta última concepção, as autoras destacam, com base em Przeworski, que o conceito de democracia em Schumpeter, ainda que minimalista, "envolve uma dimensão normativa" (2013, p. 455), mesmo que seja para substituir o conflito violento pela disputa eleitoral. Também não é possível dispensar a influência do liberalismo político sobre a concepção de democracia, e mais especificamente como uma ampla liberdade política impõe limites à manifestação do poder político pelas instituições - um elemento pouco considerado pelos autores minimalistas (SAFFON; URBINATI, 2013). Ao conformar-se uma sociedade política em que diferentes grupos concorrem eleitoralmente, as minorias também podem se inserir e almejar a participação no governo. E a dinâmica entre situação e oposição - considerada a possibilidade de que a atual maioria seja minoria após as próximas eleições - impõe limites ao poder dos governantes. Percebemos assim que quando colocamos as instituições básicas da democracia para funcionar elas tendem a ter um efeito multiplicador: "a democracia é, portanto, expansiva por natureza" (SAFFON; URBINATI, 2013, p. 458).

Destarte o procedimentalismo tal como proposto pelas autoras, ainda que se preocupe em grande medida com os procedimentos e até que ponto as regras estão sendo cumpridas, não abandona o valor normativo da democracia e não dispensa sua influência na expansão dos 
direitos e na ampliação da liberdade e capacidade dos cidadãos de participarem politicamente. Incerteza (quanto ao possível resultado das eleições); abertura e contestação (possibilidade de competição entre duas ou mais concepções políticas e que nenhuma delas defenda a eliminação das outras); participação (não apenas das elites políticas, mas dos cidadãos em geral, em um fluxo contínuo entre instituições e sociedade); e responsividade (ainda que seja aplicada a regra da maioria, os interesses das minorias também são considerados nas decisões políticas) são algumas as características do processo político tal como se conforma nessa concepção (SAFFON; URBINATI, 2013).

\section{Considerações finais}

Buscou-se neste ensaio desafiar a ideia de que o procedimentalismo de base schumpeteriana é suficiente para uma definição satisfatória do governo democrático. Isso foi feito a partir de uma resumida caracterização do minimalismo democrático, passando pelos limites de tal vertente e, enfim, possíveis pontos de abertura a partir do critério mínimo da realização de eleições. Conforme demonstrado com base em Walker (1966), O’Donnell (1999), Saffon e Urbinati (2013), ao considerarmos os sistemas políticos dinamicamente e as influências históricas que conformaram o que se apresenta hoje como democracia, não é possível reduzir a sua definição aos aspectos institucionais e à disputa pelo poder entre elites. Mesmo aqueles teóricos e teóricas que se inserem na matriz procedimentalista vieram, recentemente, a promover uma revisão dos critérios que definem um governo representativo. Tal iniciativa propiciou a construção de um entendimento mais amplo do que se define por democracia e suas variáveis.

Tal discussão teórico-conceitual está longe de se apresentar supérflua no atual contexto de recessão democrática no mundo. De que maneira avaliar a dinâmica política em cada país, as ações de governantes ou atores estatais e constatar rigorosamente se aqueles regimes se tornaram menos democráticos? Como se deduz da exposição de Glasius (2018, p. 519) "um foco excessivo nas eleições" pode obscurecer a identificação de tendências autoritárias e antiliberais, ou seja, a definição da democracia e suas variáveis é de extrema importância. É necessário perceber como determinadas políticas limitam o acesso às informações governamentais, a capacidade de denunciar violações e também a propensão de grupos marginalizados ou alvo de violência e preconceito - negros, indígenas, LGBT's e mulheres lutarem por seus direitos. Tais aspectos só podem ser avaliados a contento se nos afastamos dos procedimentos e observamos as práticas governamentais e o processo político-societário tanto em nível regional como nacional. 
Diante do crescente descrédito da classe política e das instituições frente aos cidadãos e da ascensão de líderes de extrema-direita ao poder, faz-se urgente que cientistas sociais ultrapassem o procedimentalismo de matriz schumpeteriana e vertentes que se encerram no estudo das regras e da disputa institucional. Isso não apenas do ponto de vista científico, já que impede uma devida avaliação dos regimes democráticos contemporâneos, mas também para que o conhecimento produzido por suas disciplinas seja capaz de oferecer uma contribuição àqueles atores e atrizes que exercem a cidadania. Mais do que nunca, paralelamente ao enaltecimento do pluralismo político na sociedade devemos fomentar também perspectivas interdisciplinares que rompam a dicotomia entre sociedade civil e Estado.

\section{REFERÊNCIAS}

GLASIUS, Marlies. What authoritarianism is... and is not: a practice perspective. International Affairs, v. 94, n. 3, p. 515-33, 2018.

MACKIE, Gerry. Schumpeter's Leadership Democracy. Political Theory, v. 37, n. 1, p. 128-153, 009.

MIGUEL, Luis Felipe. Democracia e representação: territórios em disputa. São Paulo: Editora Unesp, 2014.

O’DONNELL, Guillermo. Teoria democrática e política comparada. Dados, Rio de Janeiro, v. 42, n. 4, p. 577-654, 1999. Disponível em: http://dx.doi.org/10.1590/S0011-52581999000400001. Acesso em: 28 fev. 2017.

PATEMAN, Carole. Participação e teoria democrática. São Paulo: Paz e Terra, 1992.

SAFFON, Maria Paula; URBINATI, Nadia. Procedural Democracy, the Bulwark of Equal Liberty. Political Theory, v. 41, n. 3, p. 441-481, 2013.

SARTORI, Giovanni. A teoria democrática revisitada: o debate contemporâneo. São Paulo: Editora Ática, 1994.

SCHUMPETER, Joseph A. Capitalismo, socialismo e democracia. Rio de Janeiro: Fundo de Cultura, 1961.

SWEDBERG, Richard. Introduction. In: SCHUMPETER, Joseph A. Capitalism, Socialism and Democracy. New York: Routledge, p. 9-21, 2003.

URBINATI, Nadia. Representative Democracy: Principles and Genealogy. Chicago: University of Chicago Press, 2006.

WALKER, Jack L. A Critique of the Elitist Theory of Democracy. The American Political Science Review, v. 60, n. 2, p. 285-295, 1966. 


\section{Como referenciar este artigo}

BENEDITO, Sérgio Mendonça. Para uma leitura alternativa do minimalismo democrático. Rev. Sem Aspas, Araraquara, v. 8, n. 1, p. 88-102, jan./jun. 2019. ISSN: 2358-4238. DOI: 10.29373/sas.v8i1.12597.

Submetido em: 30/05/2019

Aprovado em: 18/06/2019 